\title{
Whole brain radiotherapy for brain metastases from breast cancer: estimation of survival using two stratification systems
} Gustavo A Viani*, Marcus S Castilho, João V Salvajoli, Antonio Cassio A Pellizzon, Paulo E Novaes, Flavio S Guimarães, Maria A Conte and Ricardo C Fogaroli

Address: Radiation Oncology Department, Hospital do Cancer, São Paulo, Brazil.

Email: Gustavo A Viani* - gusviani@gmail.com; Marcus S Castilho - mscastilho@gmail.com; João V Salvajoli - jvsalvajoli@uol.com.br; Antonio Cassio A Pellizzon - cpellizzon@walla.com; Paulo E Novaes - novaespe@uol.com.br;

Flavio S Guimarães - flaviosguimaraes@yahoo.com.br; Maria A Conte - contemaia@uol.com; Ricardo C Fogaroli - rcfogaroli@aol.com

* Corresponding author

Published: 26 March 2007

BMC Cancer 2007, 7:53 doi:10.1186/147/-2407-7-53
Received: 12 August 2006

Accepted: 26 March 2007

This article is available from: http://www.biomedcentral.com/I47/-2407/7/53

(c) 2007 Viani et al; licensee BioMed Central Ltd.

This is an Open Access article distributed under the terms of the Creative Commons Attribution License (http://creativecommons.org/licenses/by/2.0), which permits unrestricted use, distribution, and reproduction in any medium, provided the original work is properly cited.

\begin{abstract}
Background: Brain metastases (BM) are the most common form of intracranial cancer. The incidence of BM seems to have increased over the past decade. Recursive partitioning analysis (RPA) of data from three Radiation Therapy Oncology Group (RTOG) trials (I 200 patients) has allowed three prognostic groups to be identified. More recently a simplified stratification system that uses the evaluation of three main prognostics factors for radiosurgery in BM was developed.
\end{abstract}

Methods: To analyze the overall survival rate (OS), prognostic factors affecting outcomes and to estimate the potential improvement in OS for patients with BM from breast cancer, stratified by RPA class and brain metastases score (BS-BM). From January 1996 to December 2004, 174 medical records of patients with diagnosis of BM from breast cancer, who received WBRT were analyzed. The surgery followed by WBRT was used in $15.5 \%$ of patients and $84.5 \%$ of others patients were submitted at WBRT alone; 108 patients (62.1\%) received the fractionation schedule of 30 Gy in 10 fractions. Solitary BM was present in $37.9 \%$ of patients. The prognostic factors evaluated for OS were: age, Karnofsky Performance Status (KPS), number of lesions, localization of lesions, neurosurgery, chemotherapy, absence extracranial disease, RPA class, BS-BM and radiation doses and fractionation.

Results: The OS in I, 2 and 3 years was $33.4 \%, 16.7 \%$, and $8.8 \%$, respectively. The RPA class analysis showed strong relation with OS $(\mathrm{p}<0.0001)$. The median survival time by RPA class in months was: class I I I.7, class II 6.2 and class III 3.0. The significant prognostic factors associated with better OS were: higher KPS $(p<0.000 \mathrm{I})$, neurosurgery $(P<0.000 \mathrm{I})$, single metastases $(p=0.003)$, BS-BM $(p<0.000 \mathrm{I})$, control primary tumor $(p=0.002)$ and absence of extracranial metastases $(p=0.00 \mathrm{I})$. In multivariate analysis, the factors associated positively with OS were: neurosurgery $(\mathrm{p}<0.000 \mathrm{I})$, absence of extracranial metastases $(\mathrm{p}<0.000 \mathrm{I})$ and RPA class I $(\mathrm{p}<0.000 \mathrm{I})$.

Conclusion: Our data suggests that patients with BM from breast cancer classified as RPA class I may be effectively treated with local resection followed by WBRT, mainly in those patients with single BM, higher KPS and cranial extra disease controlled. RPA class was shown to be the most reliable indicators of survival. 


\section{Background}

Brain metastases (BM) are the most common form of intracranial cancer. They exceed the number of primary brain tumors by at least ten times and occur in about $25 \%$ of all patients with cancer. Most brain metastases originate from lung (40-50\%), breast (15-25\%), melanoma (5-20\%), and kidney (5-10\%). Brain metastases are located in the cerebral hemispheres in about $80 \%$, in the cerebellum in $15 \%$, or in the brainstem in $5 \%$ of patients [1]. The median survival of untreated patients may be as short as 1-2 months [2-4]. After radiation therapy an increase in survival is reported in the range from 3 to 6 months [4-6]. The incidence of brain metastases seems to have increased over the past decade, and may be the paradoxical result of the effectiveness of drugs that do not cross the blood - brain barrier (BBB). As a result of the increased survival in patients receiving chemotherapy, brain metastases may become symptomatic $[7,8]$. Recursive partitioning analysis (RPA) of data from three Radiation Therapy Oncology Group (RTOG) trials (1200 patients) has allowed three prognostic groups to be identified [9]. RPA class was initially developed to categorize patients treated with fractionated external beam brain RT and tested in the radiosurgical treatment of BMs [10-12]. More recently, Lorenzoni et al. [13] proposed a simplified stratification system that uses the evaluation of three main prognostics factors for radiosurgery in brain metastases; this system was called of basic score for brain metastases (BS-BM), and may be calculated by adding the scores ( 0 or 1) of three main prognostic factors: KPS, control of the primary tumor, and existence of extracranial metastases, ranging from 0 (worst condition) to 3 (best condition) [13]. In this way, the intention of present study was to analyze the prognostic factors in our series of patients with brain metastases from breast cancer treated with Whole brain radiotherapy (WBRT), with an emphasis on to test the potential improvement in survival for patients stratified by the one previously described stratification system for radiosurgery (BS-BM) and compares it with the RTOG recursive partitioning analysis.

\section{Methods}

The records of 174 patients with brain metastases, who were treated with WBRT at our institution between January 1996 and December 2004, were analyzed retrospectively. The institutional review boards granted ethical approval of the study. In the sample of the current study $(\mathrm{n}=174)$ we use 81 patients with diagnoses of breast cancer who had been part of a previous study on WBRT for Brain metastases from any site [14]. The study was approved by the institutional review boards. In present study, at diagnosis of brain metastasis, the following variables were analyzed for survival: age, location of brain metastasis, extent of disease, initial Karnofsky score, dose and fractionation of radiotherapy, surgical resection, chemotherapy, RPA class and BS-BM, as showed in table1. Chemotherapy was administered to the patients with systemic disease in activity at same time that WBRT. Supportive care (oral corticosteroids) and neurological status were not evaluated. Brain metastases were detected by contrast-enhanced cerebral computed tomography (CT) or magnetic resonance imaging (MRI). Primary tumor control was defined as remission or stable disease, without any clinical, radiologic, or laboratory findings suggestive of tumor progression at 2 months before WBRT. According to this criteria twenty patients had local or locoregional relapse, the others patients $(n=68)$ had brain metastases as first cancer diagnosis. WBRT was performed in all patients with cobalt 60 gamma rays or with $4 \mathrm{MV}$ photons of a linear accelerator. The whole brain was irradiated by usual opposed lateral fields encompassed the cranium with a $1 \mathrm{~cm}$ margin. Individual shielding blocks were fabricated for all patients, when necessary. Forty two patients received WBRT with fields included leptomeninges. The total dose was 30-40 Gy, with a median of $35 \mathrm{~Gy}$, in daily fractions of 2.0-3.0 Gy. During the study period two fractionation schemes were used: conventional fractionation with daily fractions of 2 Gray (Gy), five days per week to a planned total dose of $40 \mathrm{~Gy}(\mathrm{n}=66)$ and hypofractionation with daily fractions of $3 \mathrm{~Gy}$, five days per week to a planned total dose of $30 \mathrm{~Gy}(\mathrm{n}=108)$. Surgical resection was indicated in single brain metastases with diameter less than or equal to $3 \mathrm{~cm}$, favorable localization and controlled systemic disease. Biopsy alone and subtotal resection were done in 2 and 1 cases, respectively. All the others patients $(n=24)$ submitted to surgical resection were considered gross total resection. The supportive care (prednisone oral) was introduced at the beginning of treatment or during radiotherapy. The RPA was used to classify the patients with brain metastases Class I contained all patients with a Karnofsky performance status $(\mathrm{KPS}) \geq 70$, age $<65$ years, controlled primary tumor and no extracerebral metastases, Class III contained patients with a KPS $<70$, and Class II contained all other patients [9]. BS-BM was calculated by adding the scores ( 0 or 1$)$ of three main prognostic factors: KPS, control of the primary tumor, and existence of extracranial metastases [13]. The BS-BM ranged from 0 (worst condition) to 3 (best condition).

\section{Statistical Analysis}

The endpoint of the study was overall survival. The survival time was calculated from the starting date of WBRT to the date of death or last patient contact using the method of Kaplan Meier. Survival curves were compared using the log-rank test. The covariates examined in all cases were: age, sex, location of brain metastasis, extracranial disease, control of primary tumor, initial Karnofsky score, dose and fractionation radiotherapy schedule, surgical resection, RPA class and BS-BM. All factors with a P- 
Table I: Characteristic of treatment and patients

\begin{tabular}{|c|c|c|}
\hline AGE & MEDIAN & RANGE \\
\hline Patients & 57 & $38-82$ \\
\hline BRAIN METASTASES SCORE & NUMBER & $\%$ \\
\hline BM-S O & 34 & 19.5 \\
\hline BM-S I & 54 & 31 \\
\hline BM-S 2 & 61 & 35 \\
\hline BM-S 3 & 25 & 14.5 \\
\hline \multicolumn{3}{|l|}{ KPS } \\
\hline$<70$ & 89 & 51.1 \\
\hline$>=70$ & 85 & 48.8 \\
\hline \multicolumn{3}{|l|}{ SURGICAL RESECTION } \\
\hline Yes & 27 & 15.5 \\
\hline No & 147 & 84.5 \\
\hline \multicolumn{3}{|l|}{$\begin{array}{l}\text { DOSE(Gy) } \\
\text { FRACTIONATION (fr) }\end{array}$} \\
\hline $40 \mathrm{~Gy} / 20 \mathrm{fr}$ & 66 & 37.9 \\
\hline $30 \mathrm{~Gy} / 10 \mathrm{fr}$ & 108 & 62.1 \\
\hline \multicolumn{3}{|l|}{ NUMBER LESIONS } \\
\hline Single & 66 & 37.9 \\
\hline Multiple & 108 & 62.1 \\
\hline \multicolumn{3}{|l|}{ CHEMOTHERAPY } \\
\hline Yes & 32 & 18.3 \\
\hline No & 142 & 81.6 \\
\hline \multicolumn{3}{|l|}{ RPA CLASS } \\
\hline Class I & 39 & 22.4 \\
\hline Class II & 46 & 26.4 \\
\hline Class III & 89 & 51.2 \\
\hline \multicolumn{3}{|l|}{ LOCALIZATION } \\
\hline Supratentorial & 140 & 80.5 \\
\hline Infratentorial & 24 & 13.8 \\
\hline Both & 10 & 5.7 \\
\hline \multicolumn{3}{|l|}{ PRIMARY DISEASE CONTROL } \\
\hline Yes & 86 & 49.4 \\
\hline No & 88 & 50.6 \\
\hline \multicolumn{3}{|l|}{ EXTRACRANIAL METASTASES } \\
\hline Controlled & 80 & 46 \\
\hline No Controlled & 94 & 54 \\
\hline
\end{tabular}

value $\leq 0.05$ at univariate analysis were entered into a multivariate analysis using the proportional hazards model (Cox Regression) with confidential interval of $95 \%$.

\section{Results}

The overall survival rate in 1, 2 and 3 years was $33.4 \%$, $16.7 \%$, and $8.8 \%$, respectively (figure- 1 ). The interval between the diagnoses of breast cancer and brain metastasis was 32 months (range 0 - 74). The RPA class analysis showed strong relation with survival ( $\mathrm{p}<0.0001)$, table2 . The median survival time by RPA class in months was: class I 11.7, class II 6.2 and class III 3.0 as showed in table3. According to BS-BM system, the median survival was of 24.6 months for patients with a score of 3, 6.6 months for patients with a score of 2, 4.7 months for patients with a score of 1 , and 2.8 months for patients with a score of 0 ( $p$ $<0.0001)$, as demonstrated in table-3. Three patients were alive in moment of this analysis with a median survival time of 4.42 years (range, $3.8-5.1$ ). All these patients had 
Table 2: Univariate analyses for survival (Log Rank test)

\begin{tabular}{|c|c|c|c|c|}
\hline Variable & Number & Event (n) & $\%$ & $\mathbf{P}$ \\
\hline AGE & 132 & 106 & OS 12 months & 0.16 \\
\hline$<65$ Years & 42 & 36 & 34.8 & \\
\hline$>=65$ Years & & & 29.3 & \\
\hline KPS & & & & $<0.0001$ \\
\hline$<70$ & 89 & 75 & 21.7 & \\
\hline$>=70$ & 85 & 67 & 45.8 & \\
\hline SURGICAL RESECTION & & & & $<0.0001$ \\
\hline Yes & 27 & 20 & 66.7 & \\
\hline No & 147 & 122 & 26.9 & \\
\hline $\begin{array}{l}\text { DOSE(Gy) } \\
\text { FRACTIONATION (fr) }\end{array}$ & & & & 0.11 \\
\hline $40 \mathrm{~Gy} / 20 \mathrm{fr}$ & 66 & 55 & 27.6 & \\
\hline $30 \mathrm{~Gy} / 10 \mathrm{fr}$ & 108 & 87 & & \\
\hline NUMBER LESIONS & & & & 0.003 \\
\hline Single & 66 & 51 & 43.8 & \\
\hline Multiple & 108 & 91 & & \\
\hline CHEMOTHERAPY & & & & 0.29 \\
\hline Yes & 32 & 27 & 47.8 & \\
\hline No & 142 & 122 & 28.4 & \\
\hline RPA CLASS & & & & $<0.0001$ \\
\hline Class I & 39 & 28 & 55.6 & \\
\hline Class II & 46 & 39 & 37.7 & \\
\hline Class III & 89 & 75 & 21.7 & \\
\hline $\begin{array}{l}\text { PRIMARY DISEASE } \\
\text { CONTROL }\end{array}$ & & & & 0.002 \\
\hline Yes & 86 & 62 & 46 & \\
\hline No & 88 & 80 & 22.8 & \\
\hline $\begin{array}{l}\text { EXTRA CRANIAL } \\
\text { METASTASIS }\end{array}$ & & & & 30.001 \\
\hline Yes & 80 & 50 & 23. & \\
\hline No & 94 & 92 & 49 & \\
\hline BS-BM & & & & $<0.0001$ \\
\hline Score 0 & 34 & 33 & 11.8 & \\
\hline Score I & 54 & 52 & 24.1 & \\
\hline Score 2 & 61 & 44 & 42.6 & \\
\hline Score 3 & 25 & 13 & 69.2 & \\
\hline
\end{tabular}

single brain metastasis, high KPS, cranial extra disease controlled, submitted to surgical resection before WBRT, had RPA class 1 and BS-BM 3.

The significant prognostic factors on univariate analysis associated with better survival were: higher KPS ( $\mathrm{p}<$ $0.0001)$, surgical resection $(P<0.0001)$, single metastases $(\mathrm{p}=0.003)$, controlled primary tumor $(\mathrm{p}=0.002)$ and absence of extracranial metastases $(\mathrm{p}=0.001)$, as showed in table-2 and figures 2, 3, 4, 5, 6. In multivariate analysis, the factors associated positively with survival were: surgical resection $(\mathrm{p}<0.0001)$, absence of extracranial metas- tases ( $\mathrm{p}<0.0001)$ and RPA class I $(\mathrm{p}<0.0001)$, as demonstrated in table- 4 .

\section{Discussion}

Whole brain radiotherapy has traditionally been the standard treatment for patients with brain metastases since 1950. WBRT has been shown to effectively improve neurologic symptoms and function for patients with minimum co-morbidity. Breast cancer is one of the malignant tumors that frequently metastasize to the brain [17]. Once a diagnosis of brain metastasis has been established, prognosis is generally poor $[14,18]$. In this cohort, the overall 
Table 3: Median survival according to RPA class and BS-BM score.

\begin{tabular}{lll}
\hline $\begin{array}{l}\text { Characteristics* KPS }>=70 \text {, age }<65 \text {, controlled primary no } \\
\text { extracranial disease }\end{array}$ & RPA class I & Median survival (mo) RPA II.7 \\
\hline All others & RPA class II & 6.2 \\
KPS $<70$ & RPA class III & 3.0 \\
BS-BM & YES OR NO & Median survival (mo) BS-BM \\
Primary controlled & I 0 & \\
KPS $>70$ & I 0 & 24.6 \\
No metastases extra cranial & I 0 & 6.6 \\
SCORE 3 & three factors present & 4.7 \\
2 & two factors present & 2.8 \\
I & one factor present & \\
0 & none factor present & \\
\hline
\end{tabular}

survival rate in one year was of $33 \%$ with a median survival time 6.4 months. We previously reported a series of 270 patients with brain metastases treated with WBRT alone with or without surgical resection and, in this series, the estimated median survival was 4.6 months [14].

The table- 5 contains data from the largest studies of patients with similar diseases who were followed at different institutions, and treated with different modalities. The median survival of 6.4 months reported in our study is consistent with other reports describing the natural history and treatment with WBRT alone of breast carcinoma metastatic to the brain $[19,20]$. Researchers reporting on different treatment modalities in similar groups of patients have noted median survival times in the range of $4-16$ months after surgery with or without WBRT, SRS or WBRT alone [19-25], as showed in table-5.

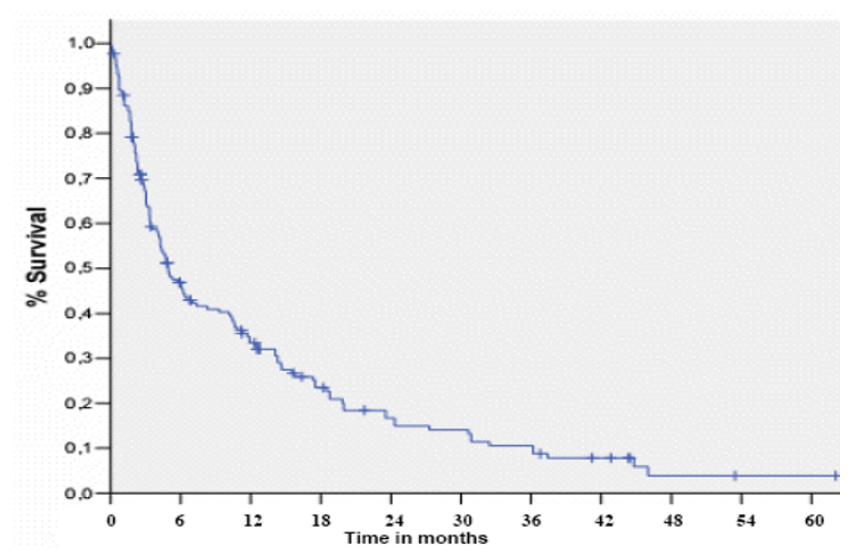

Figure I

Overall Survival (Kaplan Meier estimate).
The RTOG has evaluated a number of different radiation fractionation schemes, but median survival seems independent of the dose and schedule [26-29]. In our study, total dose of WBRT was not a statistically significant predictor of overall survival. Surgery is an important modality for patients with a single brain metastasis, particularly when favorable prognostic factors and systemic disease control are present $[30,31]$. Our data showed that patients undergoing resection of brain lesion followed by WBRT was associated with significantly better overall survival ( $p$ $<0.0001$ ) than patients submitted to biopsy or WBRT alone. Patchell et al [15], randomly assigned 48 patients with single brain metastases ( $10 \%$ with breast primaries) to surgery followed by WBRT versus WBRT alone. Patients in the combined arm experienced a longer duration of functional independence ( $38 \mathrm{v} 8$ weeks), and improved survival ( $40 \mathrm{v} 15$ weeks; $\mathrm{P}<.01$ ). Noordijk et al [30] conducted a randomized trial of 63 patients $(19 \%$ with breast primaries) that confirmed and extended these findings. Importantly, in this study, the benefit of combinedmodality therapy was seen only in patients with stable or absent extracranial disease. Patients with progressive extracranial disease at study entry achieved a median survival of only 5 months, irrespective of the allocated treatment. One additional trial failed to demonstrate a survival or quality-of-life benefit [31]. Nearly half of the patients in this trial had extracranial disease, and 10 of 43 patients randomly assigned to radiotherapy underwent surgical resection.

The end point of this cohort was to evaluate the different prognostic factors related with overall survival and to analyze the importance of recursive partitioning analysis (RPA) class (RTOG) in patients with brain metastasis. In our data, the prognostic factors in the univariate analysis associated with better survival were: Higher KPS, solitary 
Table 4: Multivariate analyses of significant factors associated with survival by Cox regression

\begin{tabular}{|c|c|c|c|c|}
\hline \multirow{2}{*}{$\begin{array}{l}\text { VARIABLE } \\
\text { SURGICAL RESECTION }\end{array}$} & \multirow{2}{*}{$\begin{array}{l}\mathbf{P} \\
<0.0001\end{array}$} & \multirow{2}{*}{$\begin{array}{r}\text { HR } \\
4.34\end{array}$} & \multicolumn{2}{|c|}{$\mathbf{9 5} \%$ confidential interval } \\
\hline & & & 2.5 & 7.14 \\
\hline SINGLE METASTASES & 0.14 & 1.08 & 0.97 & 1.21 \\
\hline$K P S>=70$ & 0.55 & 1.31 & 0.55 & 3.23 \\
\hline BS-BM & 0.58 & 0.63 & 0.12 & 3.29 \\
\hline RPA & $<0.0001$ & 1.64 & 1.32 & 2.04 \\
\hline CONTROL PRIMARY TUMOR & 0.66 & 0.92 & 0.63 & 1.34 \\
\hline NO EXTRACRANIAL METASTASES & $<0.0001$ & 2.38 & 1.63 & 3.44 \\
\hline
\end{tabular}

metastasis, surgical resection, RPA class I, BS-BM -3, control primary tumor, and absence of extracranial metastases; in the multivariate analysis RPA class I and surgical resection maintained associated with better survival, being all these prognostic factors were showed for others authors in previous studies $[9,14,16]$.

In recent publication, the Radiation Enhancing Allosteric Compound for Hypoxic Brain Metastases (REACH) study [32] tested the hypothesis that adding efaproxiral to WBRT plus supplemental oxygen would improve survival better than WBRT with supplemental oxygen alone. The results of this study suggest that efaproxiral, may improve response rates to WBRT and survival in patients with brain metastases, mainly metastases from breast cancer. Moreover, in this phase III study; KPS, number of extracranial metastatic sites, and sex had the highest statistical significance in multivariate analysis. In our study, the others factors (age, chemotherapy, dose and fractionation schedule) analyzed were not associated with any effect in survival. RPA class in this study showed similar results to
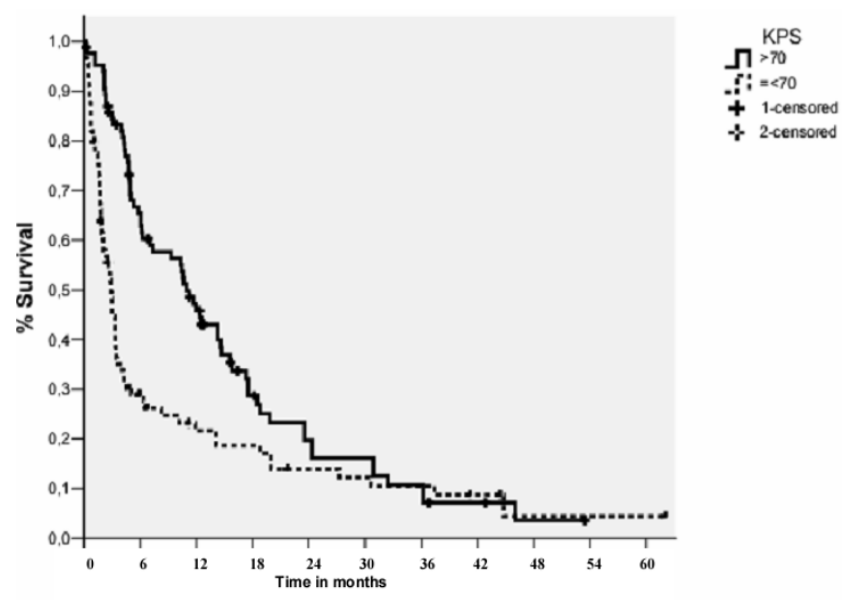

Figure 2

Overall Survival by KPS (Log Rank Test).
RTOG protocols to identify patients with different results [9], with the median survival time for class I (11.5 months), II (6.2 months) and III (3.0 months) ( $\mathrm{p}=$ $0.0001)$, respectively. In this series, the BS-BM was effective in identifying patients with different outcomes in a simple and easy manner. A BS-BM of 0 had greater specificity but lower sensitivity BS-BM. However, in our study BS-BM when compared to RPA class in multivariate analyses did not achieved significant statistical in Cox regression backward method, this data shows that RPA class is more powerful and precise than BS-BM in to predict survival for patients with brain metastases from breast cancer. Thus, theses results do not invalidated its use as a system for predict survival, only it confirms that the RPA is a more efficient system for this. But, which was the reason for this to occur? Probably this fact occurred because the BS-BM takes into account only three variables (i.e., KPS, primary tumor control, and the presence of extracranial metastases), which have been found in most studies, as well as in our own evaluation, to be the most important prognostic factors for survival. Thus it seems that less important factors had been affected indirectly by the other main factor as extracranial metastases or surgical resection

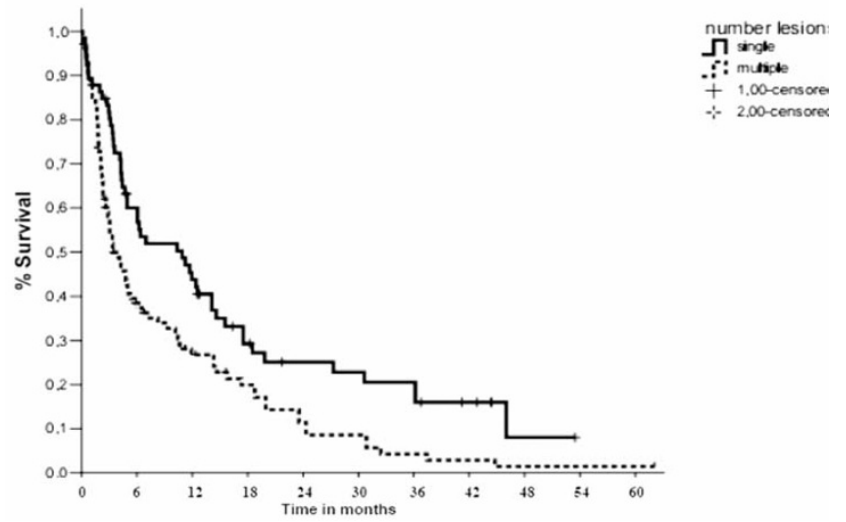

Figure 3

Overall Survival by Number of Lesions (Log Rank Test). 


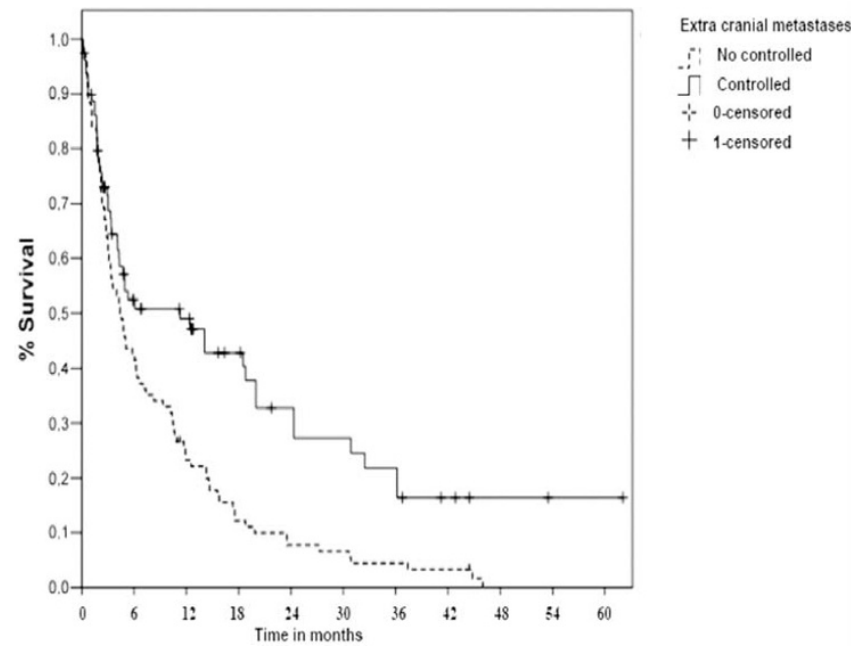

Figure 4

Overall Survival by Extra Cranial Metastases (Log Rank Test).

of lesions. Patients with three or more BMs had a greater proportion of extracranial metastases and smaller than surgical resection of lesions than those with one or two BMs (48\%vs $22 \%$ and $26 \%$ vs $58 \%$, respectively). In this way, our data showed that BS-BM system may be used effectively in patients with brain metastases treated by WBRT alone or combined with surgery.

\section{Conclusion}

In conclusion, both the stratification systems examined were able to identify quite well those patients who might or might not benefit from WBRT. RPA class was shown to be the most reliable indicators of survival. BS-BM has the advantage of focusing on only three major factors for survival. Our data suggest that patients with brain metastases

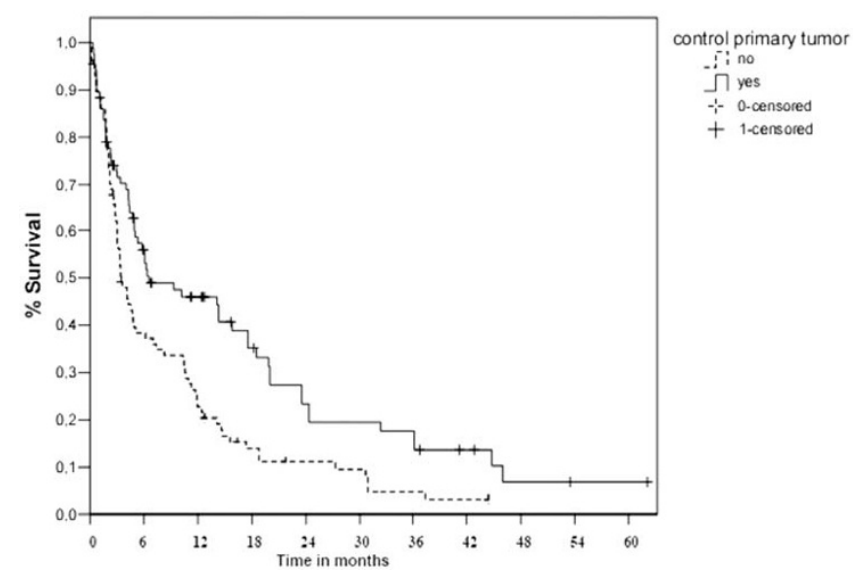

Figure 5

Overall Survival by Control primary tumor (Log Rank Test).

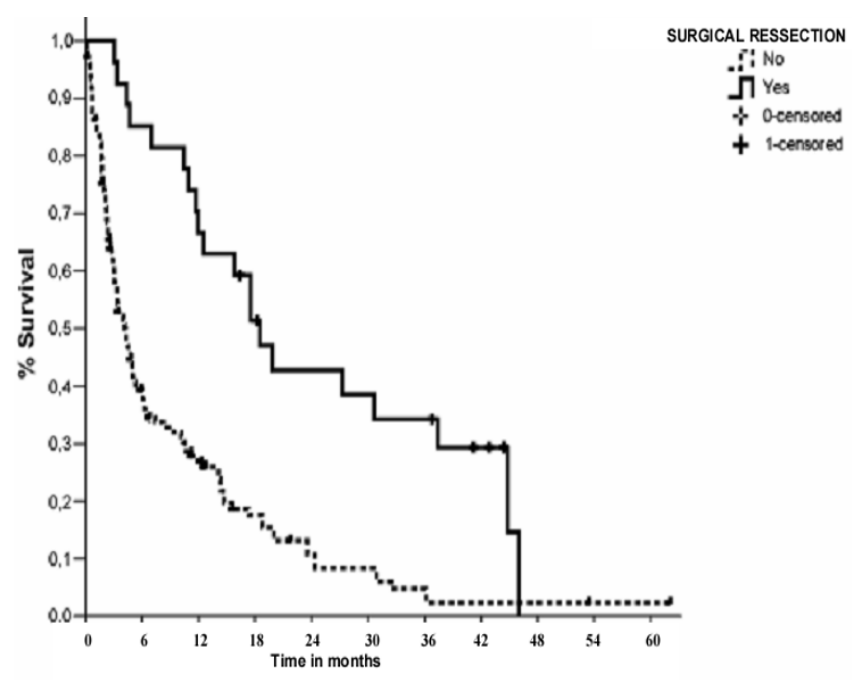

Figure 6

Overall Survival by Surgical Resection (Log Rank Test).

from breast cancer classified as RPA class I may be effectively treated with local resection followed by WBRT, mainly in those patients with single metastases, higher KPS and cranial extra disease controlled. We believe that patients presenting with a RPA Class III or BS-BM of 0 are clearly not good candidates for surgical resection followed by WBRT. Patients with RPA Class II or BS-BM of 1 in general have a poor outcome, and, in these patients, the decision concerning treatment remains difficult. Despite the generally ominous prognosis, some patients still benefit from surgical ressection. Brain metastases from breast cancer pose numerous challenges. Future areas of research may include characterization of risk factors and in this way to evaluated new approaches for the treatment of brain metastases.

\section{Competing interests}

The author(s) declare that they have no competing interests.

\section{Authors' contributions}

VG carried out the patient recruitment, acquisition and interpretation of the data. He also drafted the manuscript. VG performed the statistical analysis and drafted the manuscript. CM participated in the design of the study, carried out the patient recruitment and gave final approval of the version to be published. S JV and G FS participated in the design of the study, P AC carried out the patient recruitment and gave final approval of the version to be published, N PE carried out the patient recruitment and gave final approval of the version to be published, F R participated in the design of the study and C MA gave final approval of the version to be published. All authors read and approved the final manuscript. 
Table 5: Outcomes of the brain metastases from breast cancer treatment according to treatment modality, number of patients, median survival and prognostic factors by other researches.

\begin{tabular}{|c|c|c|c|c|}
\hline Authors & Patients(n) & Treatment & Median OS(mo) & Prognostic factors (univarate analysis) \\
\hline Firlik et al. (2I),2000 & 58 & SRS & 13 & --- \\
\hline Pieper et al.(22), I997 & 63 & Surgery+- WBRT & 16 & $\begin{array}{l}\text { Age, menopausal status, postoperative } \\
\text { RT, KPS, systemic disease }\end{array}$ \\
\hline Wronski et al. (23), 1996. & 70 & Surgery+- WBRT & 14 & $\begin{array}{l}\text { Positive estrogen receptor, meningeal } \\
\text { carcinomatosis }\end{array}$ \\
\hline Lentzsch et al. (24), 1999 & 145 & WBRT & 6.1 & $\begin{array}{l}\text { KPS, dose of RT, No. of BM, grade of } \\
\text { primary }\end{array}$ \\
\hline Mizutani et al. (19), $200 \mathrm{I}$ & 113 & WBRT & 4.0 & $\begin{array}{l}\text { KPS, No. of BM, systemic metastases } \\
\text { without bony metastasis }\end{array}$ \\
\hline Fokstuen et al. (20), 2000 & 99 & WBRT & 5.0 & No. of BM, systemic metastases \\
\hline Mahmoud-Ahmed et al. (25) 2002 & 116 & WBRT & 4.1 & KPS, WBRT dose, RPA class \\
\hline Present study. 2006 & 174 & Surgery +WBRT or WBRT & 6.4 & $\begin{array}{l}\text { KPS, RPA, single BM, resection of lesion, } \\
\text { extracranial metastase, control primary } \\
\text { tumor, BS-BM system }\end{array}$ \\
\hline
\end{tabular}

\section{Acknowledgements}

The authors thank prof. Eduardo Jose Stefano and Sergio Luís Afonso Professor of Radiation Oncology and Clinical Oncology at the Faculdade de Medicina de Marilia (FAMEMA), for editorial help.

\section{References}

I. Delattre JY, Krol G, Thaler HT, Posner JB: Distribution of brain metastases. Arch Neurol 1988, 45:74I-44

2. Coia LR: The role of radiotherapy in the treatment of brain metastases. Int J Radiat Oncol Biol Phys 1992, 23:229-238.

3. DiStefano A, Yong Yap H, Hortobagyi GN, Blumenschein GR: The natural history of breast cancer patients with brain metastases. Cancer 1979, 44:1913-1918.

4. Gutin PH: Corticosteroid therapy in patients with cerebral tumor: Benefits, mechanisms, problems, practicalities. Semin Oncol 1975, 2:49-56

5. Pladdet I, Boven E, Nauta J, Pinedo HM: Palliative care for brain metastases of solid tumour types. Neth JMed 1989, 34:10-2I.

6. Cairncross JG, Kim J-H, Posner JB: Radiation therapy for brain metastases. Ann Neurol 1980, 7:529-54I.

7. Bendell JC, Domchek SM, Burstein HJ: Central nervous system metastases in women who receive trastuzumab-based therapy for metastatic breast carcinoma. Cancer 2003, 97:2972-77.

8. Crivellari D, Pagani O, Veronesi A: High incidence of central nervous system involvement in patients with metastatic or locally advanced breast cancer treated with epirubicin and docetaxel. Ann Oncol 200I, 12:353-56.

9. Gaspar L, Scott C, Rotman M: Recursive partitioning analysis (RPA) of prognostic factors in three Radiation Therapy Oncology Group (RTOG) brain metastases trials. Int J Radiat Oncol Biol Phys 1997, 37:745-75I.

10. Sneed PK, Suh JH, Goetsch SJ: A multi-institutional review of radiosurgery alone vs. radiosurgery with whole brain radiotherapy as the initial management of brain metastases. Int J Radiat Oncol Biol Phys 2002, 53:5 19-526.

II. Sanghavi SN, Miranpuri SS, Chappell R: Radiosurgery for patients with brain metastases: A multi-institutional analysis, stratified by the RTOG recursive partitioning analysis method. Int I Radiat Oncol Biol Phys 200I, 5I:426-434.

12. Chidel MA, Suh JH, Reddy CA: Application of recursive partitioning analysis and evaluation of the use of whole brain radiation among patients treated with stereotactic radiosurgery for newly diagnosed brain metastases. Int J Radiat Oncol Biol 2000, 47:993-999.

13. Lorenzoni J, Devriendt D, Massager N: Estimation of patient eligibility using three stratification systems. Int J Radiat Oncol Biol Phys 2004, 60:218-224.

14. Saito EY, Viani GA, Ferrigno R, Nakamura RA, Novaes PE, Pellizzon CA, Fogaroli RC, Conte MA, Salvajoli JV: Whole brain radiation therapy in management of brain metastasis: results and prognostic factors. Radiat Oncol 2006, 29(I):20.

15. Patchell RA, Tibbs PA, Walsh JW: A randomized trial of surgery in the treatment of single metastases to the brain. $N$ Engl J Med 1990, 322:494-500.

16. Vecht CJ, Haaxma-Reiche H, Noordijk EM: Treatment of single brain metastasis: radiotherapy alone or combined with neurosurgery? Ann Neurol 1993, 33:583-90.

17. Tsukada Y, Fouad A, Pickren JW, Lane WW: Central nervous system metastasis from breast carcinoma, autopsy study. Cancer 1983, 52:2349-2354.

18. Petrovich Z, Yu C, Giannotta SL, O'Day S, Apuzzo MLJ: Survival and pattern of failure in brain metastasis treated with stereotactic gamma knife radiosurgery. J Neurosurg 2002, 97(Suppl 5):499-506.

19. Mizutani Y, Yamashita T, Sakamoto G: Radiation therapy for brain metastases from breast cancer by histological classification. Nippon Acta Radiol 2001, 61:89-95

20. Fokstuen T, Wilking N, Rutqvist LE: Radiation therapy in the management of brain metastases from breast cancer. Breast Cancer Res Treat 2000, 62:211-216.

21. Firlik KS, Kondziolka D, Flickinger JC: Stereotactic radiosurgery for brain metastases from breast cancer. Ann Surg Oncol 2000 7:333-338.

22. Pieper DR, Hess KR, Sawaya RE: Role of surgery in the treatment of brain metastases in patients with breast cancer. Ann Surg Oncol 1997, 4:48I-490.

23. Wronski M, Arbit E, McCormick B: Surgical treatment of $\mathbf{7 0}$ patients with brain metastases from breast carcinoma. Cancer 1997, 80: 1746- I754.

24. Lentzsch S, Reichardt P, Weber F: Brain metastases in breast cancer: Prognostic factors and management. Euro J Cancer 1999, 35:580-585.

25. Mahmoud-Ahmed AS, Suh JH, Lee SY, Crownover RL, Barnett GH: Results of whole brain radiotherapy in patients with brain metastases from breast cancer: A retrospective study. Int J Radiat Oncol Biol Phys 2002, 54:8I0-8I7.

26. Borgelt B, Gelber R, Kramer S, Brady LW, Chang CH, Davis LW, Perez CA, Hendrickson FR: The palliation of brain metastases: final results of the first two studies by the Radiation Therapy Oncology Group. Int J Radiat Oncol Biol Phys 1980, 6: I-9.

27. Komarnicky LT, Phillips TL, Martz K, Asbell S, Isaacson S, Urtasun R: A randomized phase III protocol for the evaluation of misonidazole combined nwith radiation in the treatment of patients with brain metastases (RTOG-79 16). Int J Radiat Oncol Biol Phys 199I, 20:53-58.

28. Murray KJ, Scott C, Greenberg HM, Emami B, Seider M, Vora NL, Olson C, Whitton A, Movsas B, Curran W: A randomized phase III study of accelerated hyperfractionation versus standard in patients with unresected brain metastases: a report of the Radiation Therapy Oncology Group (RTOG) 9 1 04. Int J Radiat Oncol Biol Phys 1997, 39:57I-574. 
29. Sause WT, Scott C, Krisch R, Rotman M, Sneed PK, Janjan N, Davis L, Curran W, Choi KN, Selim H: Phase I/II trial of accelerated fractionation in brain metastases RTOG 85-28. Int J Radiat Oncol Biol Phys 1993, 26:653-657.

30. Noordijk EM, Vecht CJ, Haaxma-Reiche H: The choice of treatment of single brain metastasis should be based on extracranial tumor activity and age. Int J Radiat Oncol Biol Phys 1994, 29:7II-7I7.

31. Mintz AH, Kestle J, Rathbone MP: A randomized trial to assess the efficacy of surgery in addition to radiotherapy in patients with a single cerebral metastasis. Cancer 1996, 78:1470-1476.

32. Suh $J \mathrm{H}$, Stea B, Nabid A, KresI J], Fortin A, Mercier JP, Senzer N, Chang EL, Boyd AP, Cagnoni PJ, Shaw E: Phase III study of efaproxiral as an adjunct to whole-brain radiation therapy for brain metastases. J Clin Oncol 2006, 24(I): 13-5.

\section{Pre-publication history}

The pre-publication history for this paper can be accessed here:

http://www.biomedcentral.com/1471-2407/7/53/prepub

Publish with Biomed Central and every scientist can read your work free of charge

"BioMed Central will be the most significant development for disseminating the results of biomedical research in our lifetime. "

Sir Paul Nurse, Cancer Research UK

Your research papers will be:

- available free of charge to the entire biomedical community

- peer reviewed and published immediately upon acceptance

- cited in PubMed and archived on PubMed Central

- yours - you keep the copyright 